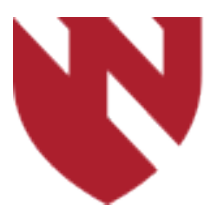

September 2020

\title{
Dobhoff Tube Placement by ENT: Annoyance vs. Life Saving
}

\author{
Jenna Berg \\ University of Nebraska Medical Center \\ Christie Barnes \\ University of Nebraska Medical Center \\ Jayme Dowdall \\ University of Nebraska Medical Center
}

Tell us how you used this information in this short survey.

Follow this and additional works at: https://digitalcommons.unmc.edu/gmerj

Part of the Higher Education Commons, and the Medicine and Health Sciences Commons

\section{Recommended Citation}

Berg, J., Barnes, C., , Dowdall, J. Dobhoff Tube Placement by ENT: Annoyance vs. Life Saving. Graduate Medical Education Research Journal. 2020 Sep 29; 2(1).

https://digitalcommons.unmc.edu/gmerj/vol2/iss1/40

This Conference Proceeding is brought to you for free and open access by DigitalCommons@UNMC. It has been accepted for inclusion in Graduate Medical Education Research Journal by an authorized editor of DigitalCommons@UNMC.For more information, please contact digitalcommons@unmc.edu. 


\section{Dobhoff Tube Placement by ENT: Annoyance vs. Life Saving}

Creative Commons License

(c) $(1) \Theta(9$

This work is licensed under a Creative Commons Attribution-Noncommercial-No Derivative Works 4.0 License. 
echocardiogram (TEE) was performed, revealing severe tricuspid regurgitation (TR) and significant right-to-left shunting. The procedure was subsequently aborted and epoprostenol initiated.

Results: A new flailed anterior leaflet of tricuspid valve (TV) was recognized during the attempted surgery, directing regurgitant blood flow through the residual sinus venosus ASD resulting in the right-to-left shunt. Unfortunately, this was never detected on
TTE. He remained in the ICU and developed impressive JVD. Repeat TEE confirmed traumatically ruptured anterior leaflet of the TV with severe TR worsened by the ASD. Overall, this resulted in depressed ejection fraction and a patient unfit for surgical repair of his injuries. Subsequently, he was taken to the OR by cardiac surgery for TV and sinus venous repair.

Conclusion: We present a patient with traumatic TR and history of congenital ASD.
Only $10 \%$ of cases of severe TR are primary due to processes directly affecting the TV. It is a rare traumatic injury usually resulting from blunt deceleration mechanisms. In fact, its prevalence may be underestimated due to subtle clinical manifestations. Therefore, it is imperative to maintain a high suspicion for such injuries, particularly in patients with a congenital cardiac history.

https://doi.org/10.32873/unmc.dc.gmerj.2.1.037

\section{You Can't Just Rub Some Dirt on It}

Alison K Bauer ${ }^{1}$, Lucas Bohannan', Jason Meredith ${ }^{1}$

${ }^{1}$ University of Nebraska Medical Center, Department of Family Medicine

\section{Mentor: Jason Meredith}

Program: Family Medicine

Type: Case Report

Introduction: Our case report demonstrates a classic presentation of compartment syndrome in an uncommon location.

Case: A 17 year-old male presented to a rural Nebraska clinic the day after sustaining a blunt trauma injury to his left anterior thigh during a high school football game. He was unable to finish the game secondary to pain. His pain increased throughout the night, leading to his presentation to clinic first thing the next morning. On exam, he was noted to have a firm, tender anterior thigh with extreme pain on passive range of motion testing. Additionally, decreased popliteal and dorsalis pedis pulses were found. An urgent CT scan revealed a vastus intermedius rupture, developing hematoma, and early compartment syndrome of the thigh. He was transferred by helicopter to a higher level of care for emergent fasciotomy. He subsequently underwent 5 procedures; ultimately our patient made a full recovery.

Discussion: This case illustrates the importance of early recognition and treatment of a potentially life-threatening orthopedic emergency despite its atypical location of presentation. Compartment syndrome of the thigh is rare compared to compartment syndrome of the lower leg and forearm. It is a clinical diagnosis requiring a high index of suspicion. Compartment pressure measurements, while available in some locations, is invasive, painful, and with questionable reliability. Early recognition and treatment of our patient's quad contusions at the time of his initial injury could have potentially prevented progression to a surgical emergency. In this case, quick and accurate recognition and evaluation led to expedited definitive, limb saving management.

https://doi.org/10.32873/unmc.dc.gmerj.2.1.038

\section{Dobhoff Tube Placement by ENT: Annoyance vs. Life Saving} Jenna Berg ${ }^{1}$, Christie Barnes ${ }^{1}$, Jayme Dowdall ${ }^{1}$

${ }^{1}$ University of Nebraska Medical Center, Department of Otolaryngology

Mentor: Jayme Dowdall

Program: Otolaryngology

Type: Original Research

Background: Dobhoff tube (DHT) placement seems like a simple procedure, but there can be serious associated morbidity and mortality including inadvertent placement of the tube into the lungs or through the skull base into the brain. ENT physicians can decrease this risk by placing the DHT through the nose under direct camera guidance in patients with elevated risk factors such as skull base fractures, prior skull base surgery, or high bleeding risk from low platelets or anticoagulation status. Placement of Dobhoff tubes in patients that do not meet these criteria consumes valuable time and resources as it requires an ENT resident to be present with a rigid nasal endoscope.
Methods: The number of DHT consults placed each month was recorded and the reason for each consult was analyzed to determine if it met criteria for a high risk patient. Each request for a DHT placement was recorded as a separate consult.

Results: There were a total of 20 DHT consults on 11 unique patients placed over a five-month period. Only three patients met criteria for being "high risk" with skull base fractures. five patients required multiple DHT placement, secondary to patient removal of the tube.

Conclusion: Less than $30 \%$ of the DHT consults in a five-month period were placed for high risk patients. This data supports revision of the current protocol to allow ENT review of the consult, and deferment to the hospital's specialized DHT placement team if the patient does not meet high risk criteria. 